\title{
Aase-Smith syndrome
}

INSERM

\section{Source}

INSERM. (1999). Orphanet: an online rare disease and orphan drug data base. Aase-

Smith syndrome. ORPHA:916

Aase-Smith syndrome type I is a very rare genetic disorder characterised by the following congenital malformations: hydrocephalus (due to Dandy-Walker anomaly), cleft palate, and severe joint contractures. 